\title{
A case of amniotic membrane transplantation in non-healing Nocardia asteroides keratitis
}

\author{
Firoozeh Rahimi • Masood Aghsaie Fard • \\ Reza Soltani Mogaddam
}

Received: 3 June 2008 / Accepted: 18 February 2009/Published online: 10 March 2009

(C) The Author(s) 2009. This article is published with open access at Springerlink.com

\begin{abstract}
A patient with severe non-healing microscopically proven Nocardia keratitis was treated with maximal topical amikacin followed by amniotic membrane transplantation (AMT) 2 months later (single-layer epithelial side-down). Epithelial healing was achieved, but neovascularization continued. This case report indicates that AMT combined with topical antibiotic provides pain relief and allows epithelial healing in severe Nocardia keratitis.
\end{abstract}

Keywords Keratitis · Nocardia •

Amniotic membrane transplantation

\section{Introduction}

Ocular infections caused by Nocardia are rare. This organism is a Gram-positive, filamentous bacterium. Ocular Nocardia infections are usually considered refractory to conventional topical antibiotics, resulting in a protracted clinical course and progressive extension of the disease [1]. Denk et al. reported that amikacin might be the drug of choice for Nocardia keratitis. If proper therapy is initiated,

M. Aghsaie Fard ( $\square)$

Farabi Eye Research Center,

Quazvin Sq.,

Tehran, Iran 1336616351

e-mail: masood219@yahoo.co.uk

F. Rahimi $\cdot$ M. Aghsaie Fard $\cdot$ R. Soltani Mogaddam

Farabi Eye Research Center, Department of ophthalmology,

Tehran University of Medical Sciences,

Tehran, Iran
Nocardia keratitis resolves with minimal scarring, with or without vascularization [2].

The main indication for amniotic membrane transplantation (AMT) is ocular surface reconstruction in persistent epithelial defects such as noninfectious corneal ulcers [3]. AMT has also been used as an adjuvant treatment for infectious corneal ulcers [4]. This case report describes a patient with Nocardia corneal ulcer unresponsive to conventional topical medication that was successfully treated with AMT.

\section{Case report}

A 20-year-old man presented to the emergency room with left eye pain from 4 days ago. He did not have any history of trauma. The patient's visual acuity in the affected eye was 20/40. His right eye was normal, and he was otherwise healthy. There were corneal edema and infiltration and an epithelial defect of $2 \mathrm{~mm} \times 2 \mathrm{~mm}$ with ring-like superficial infiltrate in a wreath pattern (Fig. 1). Gram and Giemsa stains of corneal scrapings showed Gram-positive bacteria. Three days after plating, minute white colonies appeared along the culture streak on the blood agar plate. The organism was identified as Nocardia asteroids. In vitro antibiotic susceptibility testing performed in the Nocardia isolates from the patient revealed resistance to gentamicin, ciprofloxacin, and chloramphenicol, but sensitivity to amikacin. The patient was treated with fortified amikacin (20 mg/ml). Topical antibiotic was applied frequently for the first few days. Thereafter, multidrug therapy including $20 \%$ sulphacetamide, trimethoprim-sulfamethoxazole, and amikacin did not control the infection, and the keratitis 


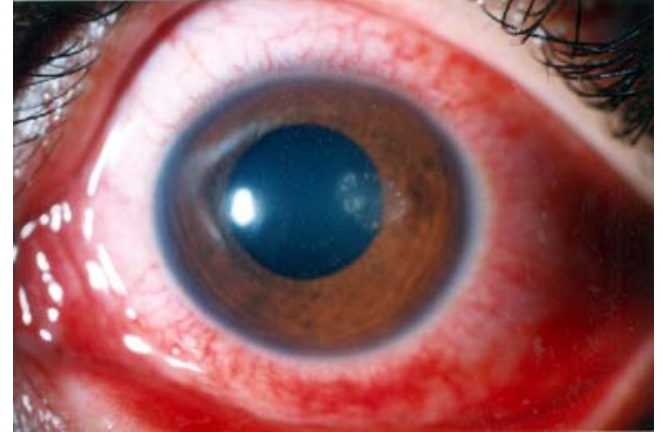

Fig. 1 Patient presentation

progressed with epithelial defect, which extended to temporal limbus after 1 month (Fig. 2). Persistent epithelial defect (PED) with new zone of keratitis and vascularization occurred after 2 months (Fig. 3).We therefore considered AMT in addition to topical antibiotics. AMT was performed under topical anesthesia. The entire cornea, including the limbus, was covered with one layer of amniotic membrane, epithelial side-down, as a patch. After 1 week, there was some pain relief, and as soon as the membrane was largely dissolved, we removed the nylon sutures and looked for PED and persistent irregular epithelium. Keratitis decreased and PED resolved, but deep vascularization did not decrease, and corneal scar persisted (Fig. 4). Then we tapered topical antibiotic to two times daily over 2 months.

\section{Discussion}

Nocardia asteroides is a Gram-positive aerobic filamentous organism. The typical clinical picture described by various authors in Nocardia keratitis is a well-defined epithelial defect with scalloped margins. The stromal infiltrate has feathery margins with satellite lesions [5]. This typical appearance of Nocardia keratitis was seen in our patient as well. The average duration of treatment in patients with

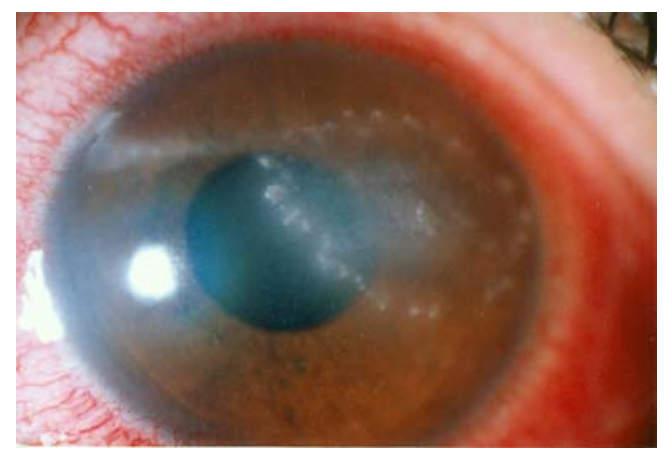

Fig. 2 Progressive keratitis after 1 month

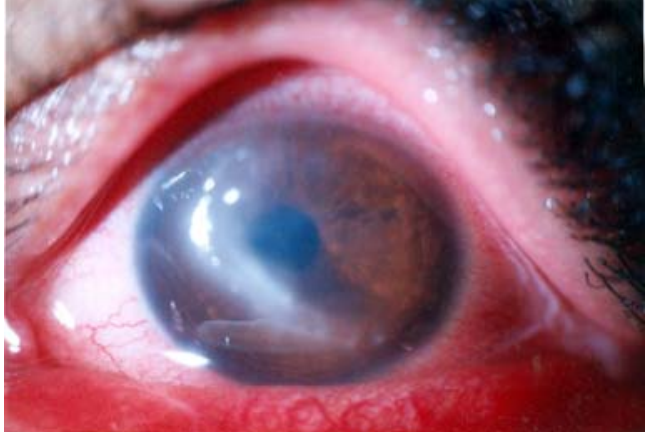

Fig. 3 New zone of keratitis after 2 months

Nocardia keratitis is 31.2 days [6]. Perry et al. have inferred that the corneal Nocardiosis like our case is longer lasting, slowly progressive, and may present with PED [7]. However, Srinivasan and Sharma have described four patients of Nocardia keratitis healing in 7-10 days with topical $10 \%$ sodium sulphacetamide and ampicillin trihydrate [8]. In this case, our patient presented with nonhealing keratitis with very prolonged clinical course, so we use adjuvant AMT.

The epithelial healing observed in our patient with AMT is consistent with reports for other corneal diseases. The amniotic membrane acts as a substrate for epithelial growth in vivo in case of PED [3]. A similar effect, with the promotion of epithelial growth, has been shown in vitro. It has also been reported that the amniotic basement membrane facilitates the migration of epithelial cells, strengthens the adhesion of basal epithelial cells, and promotes epithelial differentiation [9].

In this case, we covered the entire surface of the cornea with the amniotic membrane to optimize the limbal and corneal epithelial cell microenvironments. The "reservoir effect" of drug absorption, and the bandage properties are shared with AMT by hydrogel contact lenses [10]. In addition, AMT has anti-inflammatory or antiscarring capability, although vascularization and scaring did not decrease

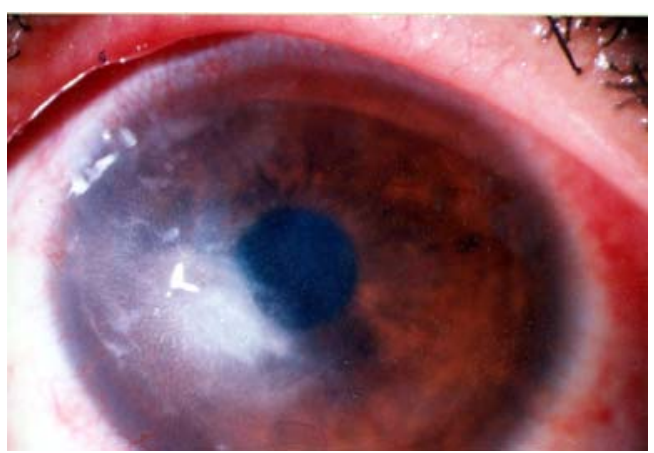

Fig. 4 Decreased keratitis after amniotic membrane transplantation 
in this case. In conclusion, this case report for the first time indicates that AMT associated with topical amikacin application is safe for the treatment of severe Nocardia keratitis.

Open Access This article is distributed under the terms of the Creative Commons Attribution Noncommercial License which permits any noncommercial use, distribution, and reproduction in any medium, provided the original author(s) and source are credited.

\section{References}

1. Huang AJW, Pflugfelder SC. Nocardial and actinomycotic keratitis. In: Pepose JS, Holland GN, Wilhelmus KR, editors. Ocular infection and immunity. St. Louis: Mosby; 1996. p. 1043-7.

2. Denk PO, Thanos S, Thiel HJ. Amikacin may be drug of choice in Nocardia keratitis. Br J Ophthalmol. 1996;80:928-9.
3. Solomon A, Meller D, Prabhasawat P, et al. Amniotic membrane grafts for nontraumatic corneal perforations, descemetoceles, and deep ulcers. Ophthalmology 2002;109:694-703.

4. Kim JS, Kim JC, Hahn TW, et al. Amniotic membrane transplantation in infectious corneal ulcer. Cornea 2001; 20:720-6.

5. Sridhar MS, Sharma S, Reddy MK, et al. Clinicomicrobiological review of Nocardia keratitis. Cornea 1998;17:17-22.

6. Rao SK, Madhavan HN, Sitalakshmi G, Padmanabhan P. Nocardia Asteroides keratitis: report of seven patients and literature review. Indian J Ophthalmol. 20000;48:217-21.

7. Perry HD, Nauheim JS, Donnenfeld ED. Nocardia asteroides keratitis presenting as a persistent epithelial defect. Cornea 1989;8:41-4.

8. Srinivasan M, Sharma S. Nocardia asteroides as a cause of corneal ulcer. Case report. Arch Ophthalmol. 1987;105:464, 1987.

9. Tseng SC. Amniotic membrane transplantation for persistent corneal epithelial defect. Br J Ophthalmol. 2001;85:1400-1.

10. Silbert JA. A review of therapeutic agents and contact lens wear. J Am Optom Assoc. 1996;67:165-72. 